\title{
TEXTURE INHOMOGENEITIES THROUGH THICKNESS BY HOT ROLLING WITH DIFFERENT HEAT TREATMENT PROCESSES OF API 5L X70
}

1 Department of Metallurgical and Materials Engineering, Universidade Federal do Ceará, Fortaleza, CE, Brazil

*mohammad@alu.ufc.

\author{
Mohammad Masoumi *1, Hamilton Ferreira Gomes de Abreu1
}

\begin{abstract}
In this work the influence of different thermomechanical paths and heat treatments on crystallographic texture through thickness of API 5L X70 pipeline steel has been studied by using X-ray diffraction, electron backscattered diffraction (EBSD) and scanning electron microscope (SEM). The samples were hot rolled at $1000{ }^{\circ} \mathrm{C}$ to $44 \%$ and $67 \%$ reduction in thickness and then heat treatment processes such as annealing, water quenching and quench-tempering were done to evaluate microstructure and crystallographic texture changing through thickness. Banded ferrite-pearlite microstructure has shown in as received material, was changed to acicular ferrite, quasipolygonal ferrite, granular bainite, martensite and retained austenite during different heat treated processes. In rolling, inhomogeneity of texture has often been observed due to friction between rolls and material, in this manner, rolling schedules induced crystallographic texture dominated by the $\{112\} / \mathrm{ND}$, $\{111\} / / \mathrm{ND}$, and $\{011\} / / \mathrm{ND}$ fibers, which $\{110\} / / \mathrm{ND}$ fiber was formed mainly through surface plan but $\{112\},\{111\} / \mathrm{ND}$ and $\{001\}\langle 110\rangle$ texture component were developed in mid plan of samples. As a result, better understanding of these processes is the key to improving and optimizing the structures of both current and future pipeline steels.
\end{abstract}

Idex Terms - Thermomechanical path; Crystallographic texture; Shear deformation

\section{INTRODUCTION}

$\mathrm{S}_{\mathrm{o} \text { i }}^{\mathrm{in}}$ ince pipeline steels are extensively used for transportation of oil and natural gas for long distances, the demand for them has been increased considerably in recent years [1]. Mechanical properties of steels have been improved through control microstructure and hardness, reduction in inclusion morphology, and use of low segregated uniform microstructures [2]. In this study control of crystallographic texture through thickness has been proposed as a means to improve mechanical properties.

Asbeck and Mecking [3] showed that the texture inhomogeneity results from inhomogeneous shear deformation occurring during rolling, whereas the surface texture is caused by the surface roughness of the rolls. This shear strain has the value zero in the center plane of the sheet and reaches a maximum value either at the surface or possibly also in an intermediate layer, depending on the geometrical conditions. High value of hardness at surface is resulted by work hardening caused by resultant shear strain due to friction between rolls and sheet. It is found that large amount of additional shear strain is applied to surface of cold rolled sheet due to friction between rollers and sheet surface when rolling is carried out without lubrication [4]. Remaining shear stress caused textural and micro structural inhomogeneity along thickness direction.

Most analyses of the textures developed on rolling, assume that plane strain conditions apply and that the texture develops uniformly through the thickness of the material. However, this is rarely true in practice, and through-thickness variations are commonly found [5]. The two most important parameters are the rolling geometry and the friction. Within the roll gap there is a neutral plane in which the relative velocity of the sample and rolls changes direction. Shears of opposite sense are imposed on the deforming material on either side of the neutral plane, and thus material near the sample surface undergoes shear in both directions. The texture gradients though the sheet are greatest for small diameter rolls, small reductions per pass, and for thick sheet. The texture heterogeneity becomes more pronounced under conditions of high friction. The surface shear textures developed in bcc metals include $\{001\}<110\rangle$ and $\{111\}<110\rangle$ components. However, through-thickness variations in texture are also influenced by the properties of the material [6].

Heat treating may be defined as the controlled heating and cooling of a metal in order to obtain a desired microstructure and consequently desired properties. Carbon and low alloy steels are the most widely used alloys in oil and gas exploration and production. One of the reasons for this is their versatility: a wide range of properties can be obtained through an appropriate heat treatment. The basis for heat treating carbon and low alloy steels is that they have several different stable crystal structures depending on temperature. By manipulating the crystal structures during heat treatment, the desired microstructure and mechanical properties can be obtained in the end product provided that the size of the part does not exceed the hardenability limits of the alloy used. The 
most common type of heat treatment imposed on carbon and low alloy steels is a three- to four-step process consisting of austenitizing, quenching and tempering, normalizing, austenitizing, quenching, and tempering. This transformation hardening process is generally referred to as quench and tempering process [7].

In the present work, a rather simple interpretation of textures could be given by comparing them with the orientation changes during different rolling reduction and heat treatment processes. It has been shown that these contradictions are due to a systematic change of texture across the specimen thickness. Textures are determined in various distances from center plane such as surface plan, one-quarter plan and center plan, a distinct continuous texture change occurs across the sample thickness.

\section{EXPERIMENTAL PROCEDURE}

The starting material was a piece of API $5 \mathrm{~L} \times 70$ with 8.5 $\mathrm{mm}$ thickness. The chemical composition of the as-rolling is given in Table1. The slab sample was reheated to $1200^{\circ} \mathrm{C}$ and held for $1 \mathrm{~h}$ and then conventionally hot rolled at $1000{ }^{\circ} \mathrm{C}$ to 5 and $3 \mathrm{~mm}$ in 3 and 4 passes, respectively in a laboratory mill. After hot rolling, one part of the strips were cooled in air to room temperature, and the other part quenched in water then tempering processes were done in 600,650 and $700{ }^{\circ} \mathrm{C}$.

For microstructural analysis, all samples were ground with 120, 220, 500, 1200 grit $\mathrm{SiC}$ paper and then polished with 6, 3 and $1 \mu \mathrm{m}$ diamond paste suspension, respectively. Then, samples were etched with $2 \%$ nital solution to determine microstructure by scanning electron microscopic.

Macro-texture measurements have been carried out at different layers of the pipe thickness along the RD-TD sections to study the non-homogeneity of texture and grain boundary misorientation distributions through the thickness. These studies were carried out the rolling plane of surface, one-quarter and center plan of samples. Three incomplete pole figures, $\{110\},\{200\}$, and $\{211\}$, were measured using a Co goniometer. The orientation distribution function (ODF) of each sample was determined from the measured pole figures using the M-text software. The Bunge's Euler angles were adopted to describe orientations and the $\varphi 2=45^{\circ}$ section of Euler space was used to display the computed ODFs.

Scanning electron microscopy (SEM) and Electron Backscatter Diffraction (EBSD) were done in surface and center plane, to perform metallographic inspections and to collect microtexture data of test samples on the transverse (RD-ND) plane. The microstructures were revealed by etching each sample in $2 \%$ Nital at room temperature for $15 \mathrm{~s}$. Grain boundaries were defined in EBSD-derived microstructures by the presence of a point-to-point misorientation greater than $3^{\circ}$.

Table 1. Chemical analysis (emission spectrometry) of API X70 (in $\mathrm{wt} \%)$.

\begin{tabular}{llllll}
\hline $\mathrm{C}$ & $\mathrm{Si}$ & $\mathrm{Mn}$ & $\mathrm{S}$ & $\mathrm{Al}$ & $\mathrm{Cr}$ \\
\hline 0,0991 & 0,2585 & 1,6641 & 0,0059 & 0,042 & 0,0214 \\
\hline $\mathrm{P}$ & $\mathrm{Ni}$ & $\mathrm{Mo}$ & $\mathrm{Nb}$ & $\mathrm{Ti}$ & $\mathrm{V}$ \\
\hline 0,0182 & 0,0223 & 0,8164 & 0,0615 & 0,019 & 0,0496 \\
\hline
\end{tabular}

\section{RESULTS AND DISCUSSIONS}

\section{A. Microstructural evolution in processing}

Various thermomechanical treatment make different microstructure in same material, the microstructures of some selected samples by SEM are shown in figure 1. The starting X70 material possesses a banded ferritic - pearlitic microstructure (fig. 1a) with quasi-polygonal ferrite due to the forming process and indications of partial recrystallization during hot rolling process, with average hardness $165 \pm 5 \mathrm{HV}$. Furthermore the ferrite presented a hardness of $135 \pm 5 \mathrm{HV}$, and ferrite grain size was measured $8 \pm 1 \mu \mathrm{m}$. Austenization above the Tnr temperature with cooling in air consists of upper bainite and acicular ferrite (fig. 1b). Bainite sheaves were nucleated at the prior austenite grain boundaries and surrounded by iron carbide particles. These present structures are difficult to determine grain size, but generally, average grain size and hardness were estimated, $13 \pm 1 \mu \mathrm{m}$ and $195 \pm 5$ $\mathrm{HV}$, respectively. With the austenization heat treatment applied, the grain size showed an increase over the samples as received, from 8 to $13 \mu \mathrm{m}$ are provided. This phenomenon was expected due to annealing temperature and time in the furnace, i.e. the higher the residence time and the heating temperature, the larger the resulting grain size. The microstructures after deformation were consisted of polygonal ferrite and quasipolygonal ferrite grains (fig.1 c) as a result of fully recrystallization at higher temperature range $\left(>900{ }^{\circ} \mathrm{C}\right)$, the increase in hardness from $165 \mathrm{HV}$ to $190 \mathrm{HV}$ has been associated with the ferrite grain refinement.

Thermo-mechanical controlled rolling (TMCR) followed by rapid cooling formed martensitic structure after the waterquenching from final rolling temperature (fig. $1 \mathrm{~d}$ ) with highly increasing in hardness to reach $348 \pm 5 \mathrm{HV}$. Quenching generates large numbers of deformation bands and dislocation for the precipitation of composite carbonitride and oxide of $\mathrm{Ti}$ and $\mathrm{Nb}$. These precipitates at deformation bands and dislocations caused intragranular-ferrite transformetion and separated lath-bainite, but restrained quasi-polygon ferrite transformation [8]. During the intragranular-ferrite transformation process, surplus carbon was released to the austenite and the fine M/A island formed. The microstructures of quenched in water and tempered at three different temperatures 600,650 and $700{ }^{\circ} \mathrm{c}$ for one hour are shown in Fig. $1 \mathrm{e}$ and f. At $600^{\circ} \mathrm{c}$, the microstructure of X70 consists of bainitic ferrite and granular bainite. Original austenite grain boundary is clear, and strip M/A constituent exists at the grain boundary. The interior sub-lath of some of GB began to merge and its boundary disappeared. After being tempered at 650 and $700{ }^{\circ} \mathrm{c}$ the microstructure of $\mathrm{X} 80$ is still bainitic ferrite and granular bainite. Original austenite grain boundary is not clear, and the M/A constituent on grain boundary is fully decomposed. Bainite ferrite lath merges to form wide laths. Boundaries of laths become fuzzy. The strip M/A constituent between original laths is broken down, refined, leading to exist in the interior of wide laths. Inner substructure of granular bainite disappears, M/A island turns into tiny and spotty particles because of gradual decomposition. The microstructure mainly consisted of intergranular ferrite with 
bainite, It is clear that intragranular-ferrite and separated fine lath-bainite have high strength and good toughness. During the tempering process, surplus carbon and other alloys were expelled from martensite to nearby austenite, which enriched the austenite with. When the temperature continued to decrease, those parts of the austenite enriched with carbon transformed to pearlite and other parts of the austenite enriched with carbon transformed to intragranular-ferrite and fine $\mathrm{M} / \mathrm{A}$ island.

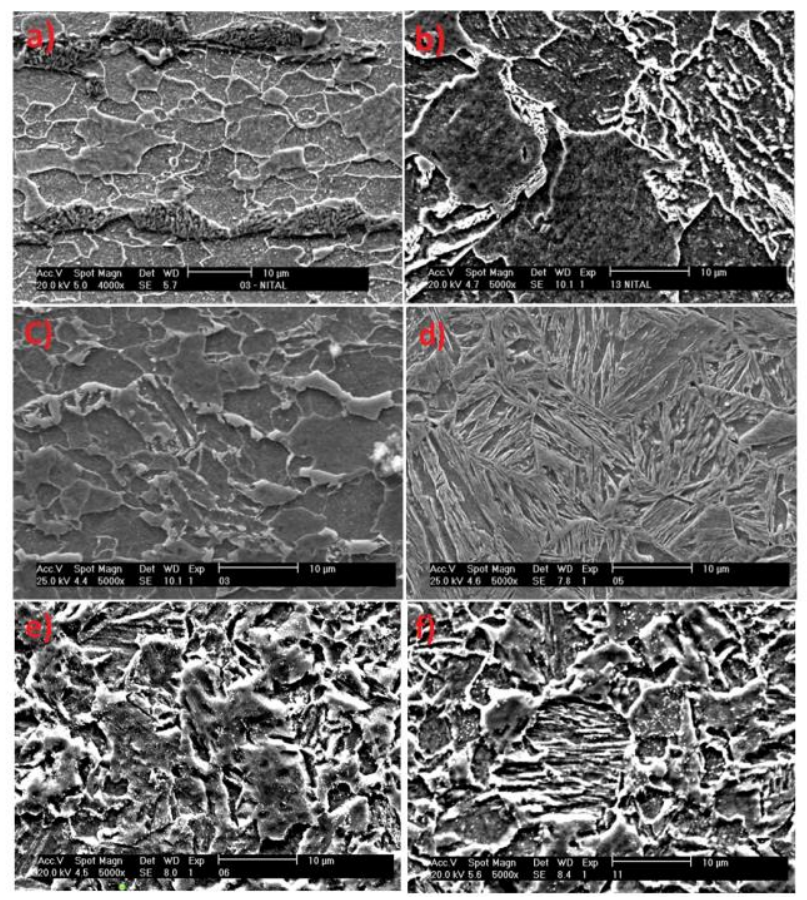

Figure 1. Micrographs of the material a) starting, b) heat solution treatment, c) $67 \%$ reduction, d) quenched in water, e) tempered at $600{ }^{\circ} \mathrm{C}, \mathrm{f}$ ) tempered at $650{ }^{\circ} \mathrm{C}$

\section{B. Textural evolution in processing}

Although there are numerous papers on the rolling texture of bcc material, the texture inhomogeneity of its formation is not clarified yet. One promising way to better understand the underlying orientation changes of the crystallites is to follow the texture formation during rolling by means of three dimensional ODF instead of pole figures mostly used till now. Since the later ones give only incomplete information about the true orientation distribution, only the use of ODF's allows the observation of many details possibly important for the interpretation of texture formation [5]. By means of quantitative ODF analysis this texture transition through thickness, some great and useful facts have been revealed, so the texture of material during deformation and post-heat treatment has been studied in three different plans; surface, one-quarter and center plane. Texture evaluation through thickness during various thermomechanical paths has been shown in fig. 2 .

The temperature of deformation may influence the development of texture, as many industrial rolling operations are carried out warm and hot, this is an important parameter. Factors which may alter the texture during rolling at elevated temperatures include an increased rate of dynamic recovery and recrystallization, an increase in the homogeneity of deformation or the operation of different slip systems [2]. A nearly random texture is typical of low carbon steels finished using an austenitic hot rolling strategy which was shown as starting material (fig.2a), however the strong \{001\}//ND texture have a harmful effect on mechanical properties. Because in these grains, the $\{001\}$ cleavage planes are oriented almost parallel to the rolling plane, facilitating crack propagation along them, and thus along the rolling plane of the pipe wall [9], beside cleavage along the $\{001\}$ planes were found to be the main cause of transgranular crack growth in the rolling plane as well as of crack deflection in the ND direction [10].

As mentioned beforehand rolling makes shear bands during deformation process through material and it causes changing the deformation texture in sample. Shear bands tend to cause rotation of the material about the transverse direction, and this may lead to changes in intensity of the texture and intensity redistribution along the $\{110\}$ fibre. In particular, the Copper component is weakened and the Brass and Goss components strengthened by shear banding [6]. The complicated textures could be interpreted as superposition of the textures of the different layers of the sample and their development was shown to be largely determined by formation and subsequent dissolution of shear textures in connection with the reduction of specimen thickness during rolling. In this respect, at the surface plan which shear value reached a maximum, $\{001\} / / \mathrm{ND}$ planes were eliminated and $\{110\} / / \mathrm{ND}$ planes were increased. $\{110\}$ planes are considered to be the main slip planes in the bcc materials so these type of grains can rotate under deformation which let them be more resistance and improving mechanical properties. Nave, Barnett and Beladi, in 2004, noted that the Goss orientation in the recrystallization texture of the steel arises due to the presence of shear bands within grains with orientation $\{111\}<112>$ and $\{001\}<110\rangle$. These bands arise when having sizes in steels initial coarse grain and carbon atoms in solution.

The post heat treatment behaviour of a deformed metal is dependent not only on the overall stored energy, but more importantly on its spatial distribution. On a local scale, inhomogeneity of stored energy will affect the nucleation of recrystallization, and largerscale heterogeneity will influence the growth of the new grains. In order to predict the annealing behaviour, it is therefore important to determine the distribution of the defects resulting from deformation [6]. Rapid quenching in water then tempering after hot rolling makes a new microstructure which is rather inhomogeneity across thickness [11]. Higher intensity of the $\{001\}$ fiber and gamma fibre $(\{111\}\langle u v w\rangle)$ could be obtained at appropriate choice of the finishing temperature at hot rolling and optimum annealing conditions immediately following the last pass at hot rolling. Hot band annealing with phase transformation lead to an enhanced intensity of the Goss and cube texture. It has also been domenstrated that a coarse grained hot band structure gives a higher intensity of Goss texture [12]. Fig.2 d, shows the tempered sample after quenching exhibit its ideal $\gamma$ fibre texture characterized by the presence of $\{111\}\langle 110\rangle$ and $\{111\}\langle 112\rangle$. $\gamma$-fibre texture represents $\langle 111\rangle / / \mathrm{ND}$ texture, where $\langle 111\rangle$ direction of the crystal are aligned along the 
normal direction of the sample. In contrast, already undesirable $(001)<110>$ texture component is exist in center pane of all samples during thermomechanical paths. The results confirm why the crack would more likely nucleate and propagate in center, because the lack of enough slip planes in this region gets more prone of crack formation. a)

b)
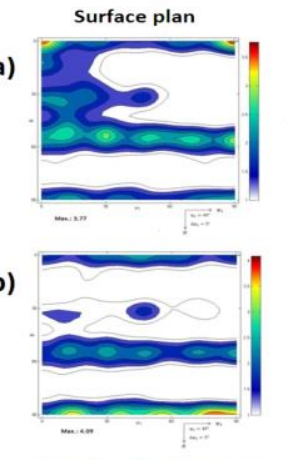

c)

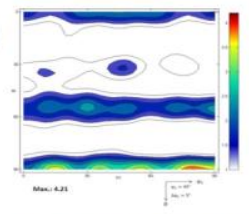

d)

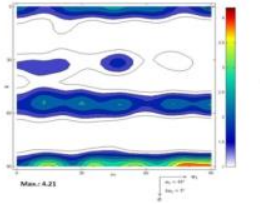

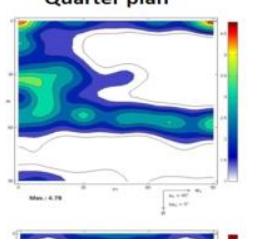
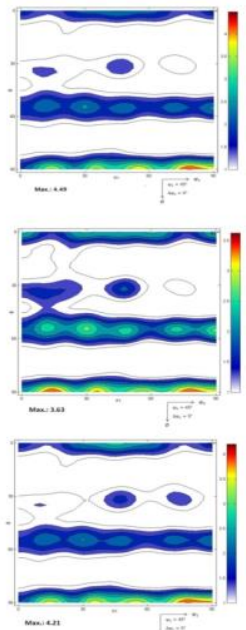
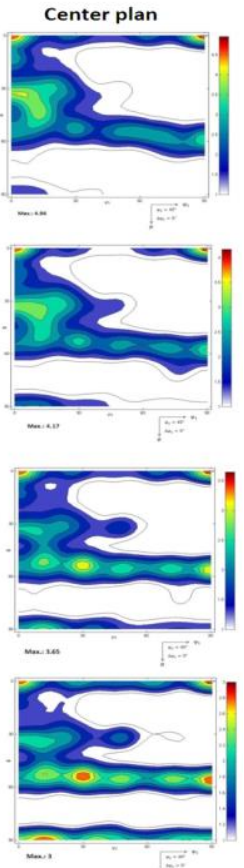

Figure2; Texture components in a constant $\varphi 2=45^{\circ}$ section of the ODF a) Starting, b) Hot deformed material $67 \%$ red., c) water quenched after deformation and d) Tempered at $700^{\circ} \mathrm{c}$. a)

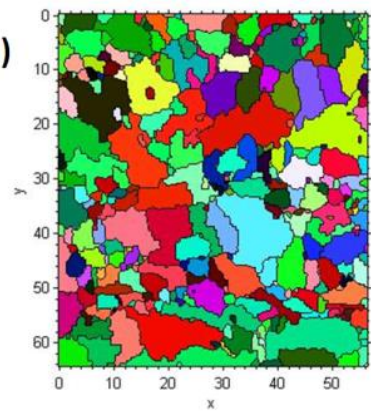

b)

c)

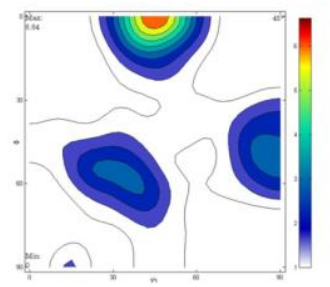

d)

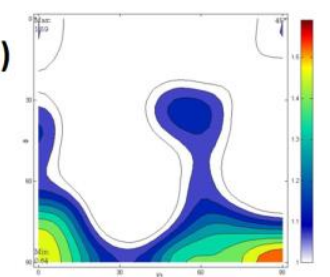

Figure 3; Crystal orientation mapping for deformed material a) center plan, b) surface plan., ODF in $\varphi 2=45^{\circ}$ c) center plan and d) surface plan

\section{C.EBSD studies}

The crystallographic characteristics of the deformed specimen at center and surface plane have been examined with the EBSD technique. The EBSD crystal orientation maps and theirs ODF are presented in Fig. 3. High angle grain boundaries (HAGB) were defined as having misorientation greater than $15^{\circ}$. Generally these types of grain boundaries can be used as a crystallographic criterion showing the main grain boundaries. Low angle boundaries were defined as having misorientation of $2-15^{\circ}$. Each color indicates that the crystal orientation changes only from 2 to $15^{\circ}$ with its neighbor points.

In accordance with the results of previous section, EBSD measurements carried out in this study was to determine the distribution, or texture, of grain boundaries in both center and surface plan. The deformation process cooling in air after hot rolling gives a new recrystallized structure, which is rather inhomogeneous across the thickness. The result shows the $(001)\langle 01 \overline{0}\rangle$ is the main texture component in center plan region, in contrast $\{110\}$ fiber with $(110)<001>$ and $(110)\langle 11 \overline{0}\rangle$ is the main texture in surface plan. Moreover, after hot rolling orientation gradients are observed within the grains, which may imply the existence of low angle grain boundaries. The number of low angle grain boundaries was found to be much higher on the center which gradually decreased towards the surface region, from $8.17 \%$ to $4.53 \%$. shear deformation due to contact between rolls and strip makes the more deformation and cause higher percentage of dislocation in surface plan in compared of center, so even after dynamic recrystallization during hot deformation.

\section{Conclusion}

- Shear strain induced texture inhomogeneity across the thickness.

- Controlled hot rolling schedule creates $\{111\}$ ND, $\{112\}$ ND and $\{110\}$ ND in samples.

- Shear strain induced results a higher fraction of $\{110\}$ ND in surface plane and undesirable $\{001\}$ ND creates in lack of it in center plane.

- The number of high angle grain boundaries was found to be much higher on the surface plane which gradually decreased towards the mid-thickness region.

\section{ACKNOWLEDGEMENTS}

The authors would like to appreciate the help of the research board of the Universidade Federal do Ceará and CAPES for the financial support and Laboratório de Caracterização de Materiais (LACAM) for provision of research facilities of this work.

\section{REFERENCES}

[1] M.A. Mohtadi-Bonab, J.A. Szpunar, L. Collins, R. Stankievech. Evaluation of hydrogen induced cracking behavior of API X70 pipeline 
steel at different heat treatments. International journal of hydrogen energy xxx (2014) 1-13.

[2] V. Venegas, F. Caleyo, T. Baudin, J.H. Espina-Hernández, J.M. Hallen. On the role of crystallographic texture in mitigating hydrogen-induced cracking in pipeline steels. Corrosion Science 53 (2011) 4204-4212.

[3] H. O. Asbeck and H. Mecking, Mater. Sc. Engg., Vol. 34 (1978), p. 111.

[4] M. Masoumi, E. Emadoddin. Interface characterization and formability of two and three-layer composite sheets manufactured by roll bonding. Materials and Design 44 (2013) 392-396

[5] J. Pospeich, K. Lucke. Development of Rolling Textureand Texture Inhomogeneities of Single and Polycrystalline Copper. Acta Metallurgical. Vol. 26. Pp. 1709-1719.

[6] RECRYSTALLIZATION AND RELATED ANNEALING PHENOMENA. F.J. HUMPHREYS. University of Manchester Institute of Science and Technology, UK. M. HATHERLY. University of New South Wales, Australia. 2004.

[7] Heat Treatment and Testing of Large Cross Section and Critical Section Components. API Recommended Practice 6th Second Edition, xxx 2011.

[8] Ling Zhongqiu, Fang Jian, Zhou Yong, Yuan Zexi. Influence of Quenching On-line on Properties of X70 Steel for Sour Service Seamless Pipe. 2012 International Conference on Future Energy, Environment, and Materials.

[9] V. Venegas, F. Caleyo, J.M. Hallen, T. Baudin, R. Penelle, Role of crystallographic texture in hydrogen-induced cracking of low carbon steels for sour service piping, Metall. Mater. Trans. A 38 (2007) 1022 1031.

[10] S. Nafisi, M.A. Arafin, L. Collins, J. Szpunar. Texture and mechanical properties of API X100 steel manufactured under various thermomechanical cycles. Materials Science and Engineering A 531 (2012) $2-11$

[11] Hai-Tao Liu, J. Schneider, Hua- Long Li, Yu Sun, Fei Gao, Hui- HuLu, Hong-Yu Song, Lei Li, Dian- Qiao Geng, Zhen- Yu Liu, Guo- Dong Wang. Fabrication of high permeability non-oriented electrical steels by increasing <001> recrystallization texture using compacted strip casting processes. Journal of Magnetism and Magnetic Materials 374 (2015) $577-586$.

[12] S. Chen, J.Butler, S.Melzer. Effect of asymmetric hot rolling on texture, microstructure and magnetic properties in a non-grain oriented electrical steel. Journal ofMagnetismandMagneticMaterials368(2014)342-352. 